Article

\title{
Persea schiedeana: A High Oil "Cinderella Species" Fruit with Potential for Tropical Agroforestry Systems
}

\section{Jay Bost}

Tropical Plant and Soil Science Department, University of Hawai'i, St. John Plant Science Lab, Room 102, 3190 Maile Way, Honolulu, HI 96822, USA; E-Mail: jbost@hawaii.edu;

Tel.: +1-808-956-8351

Received: 18 October 2013; in revised form: 18 November 2013 / Accepted: 17 December 2013 / Published: 23 December 2013

\begin{abstract}
Persea schiedeana, a close relative of avocado (Persea americana), is an important part of agroforestry systems and diets in parts of Mesoamerica, particularly in the coffee growing areas of southeastern Mexico and Guatemala, where it is known as chinene, coyo, and yas. Little research attention has been given to this species, other than as a rootstock for avocado. Research carried out in six villages composing the Comité de Recursos Naturales de la Chinantla Alta (CORENCHI) in Oaxaca, Mexico shows that Persea schiedeana has potential as a supplement to avocado production in subsistence systems and as a potential oil crop in more market oriented agroforestry systems. This survey of Persea schiedeana in the Chinantla area reports on the ethnoecology and management of chinene, as well as on the morphological diversity of the fruit in the area. High morphological diversity for fruit characters was noted and it is suggested that artificial selection has occurred and been modestly successful for desired fruit characters. Superior fruiting trees, identified during village level "chinene fairs" were targeted for vegetative propagation as part of a participatory domestication project. Such superior genotypes hold potential for addressing food security and creating marketable products in tropical areas around the globe.
\end{abstract}

Keywords: Persea; underutilized crops; agrobiodiversity; agroforestry; domestication; in situ management; oil crops; participatory domestication; avocado; ethnobotany 


\section{Introduction}

While there are thousands of edible plants on the planet, humans increasingly rely on fewer and fewer species and cultivars to feed ourselves, ultimately with negative effects on human health and agricultural sustainability [1,2]. Both within the scientific community [3-5] and the emerging coalescent food/agricultural revitalization movement [6-9] there are calls to document, preserve, and promote the diversity of plant species we consume and the diversity of varieties within these species (known as "agrobiodiversity"). Many species with considerable potential to contribute to food security are considered "under-utilized" and/or under-studied while being important components of local and regional specific diets [10]. Research and efforts to promote continued use of such "Cinderella species" locally, and the spread of these species through their introduction to new growing areas has been called for from numerous corners [11]. Many of these species are multi-purpose species, which can serve as NTFPs (non-timber forest products) if wild harvested [11-16] or as AFTPs (agroforestry tree products) if cultivated in extensive rather than intensive agricultural systems [17]. They typically have considerable traditional knowledge associated with them $[18,19]$.

This paper presents research on such a species, Persea schiedeana, called "chinene" or "chinini" in southeastern Mexico, a close relative of avocado (Persea americana), and which is consumed locally in specific areas from Mexico to Colombia in much the same way that avocado is consumed [20-23]. Its attractive features are that it has a very high oil content, much higher than West Indian varieties of avocado, which grow in the same altitudes in which Persea schiedeana is found; $24.7 \%-36 \%$ in P. schiedeana vs. 4\%-7\% in West Indian avocados [21,24]. Persea schiedeana fruits differ from those Persea americana in having beige or cream colored flesh (Figures 1 and 2). In the study area, Persea schiedeana yields fruit during a lull in avocado production, and in a relatively scarce time in general in the local diet, thus contributing to local food security.

Figure 1. Cross-section of mature Persea schiedeana.

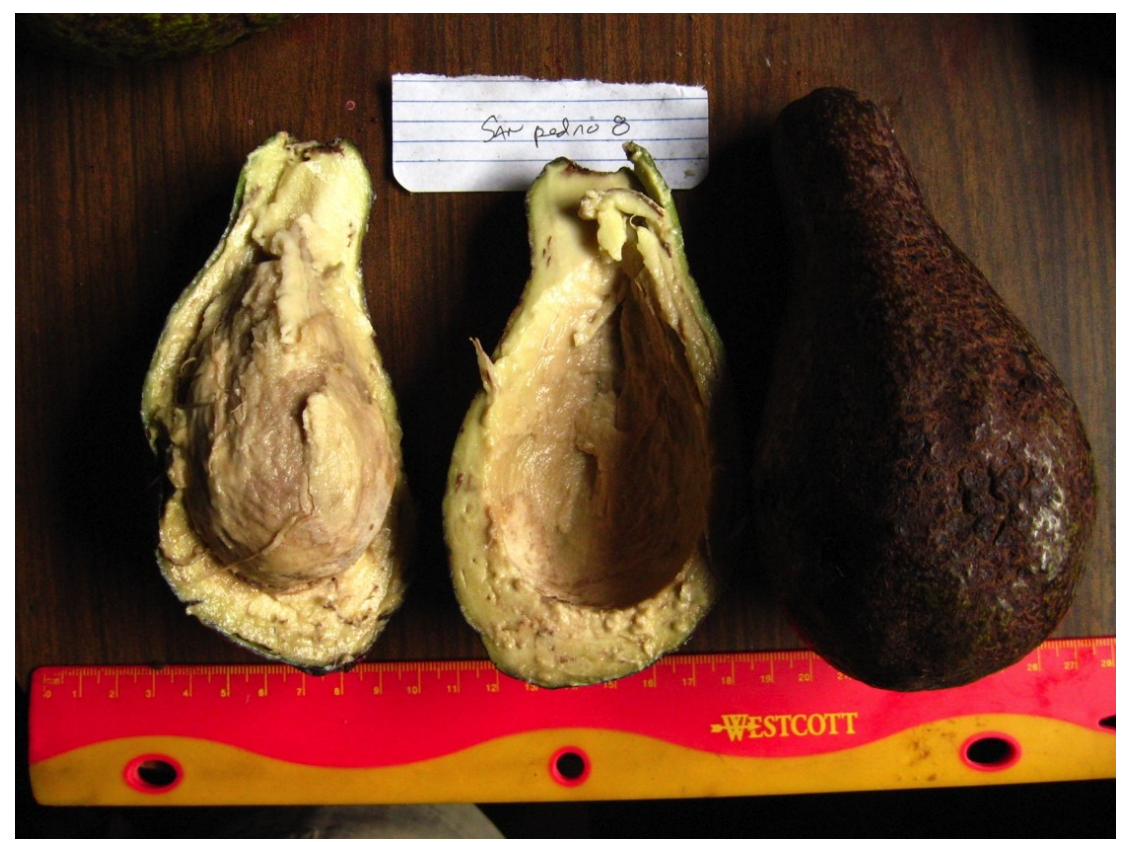


Figure 2. Collection of fruits from various trees demonstrating the diversity of fruit forms and colors.

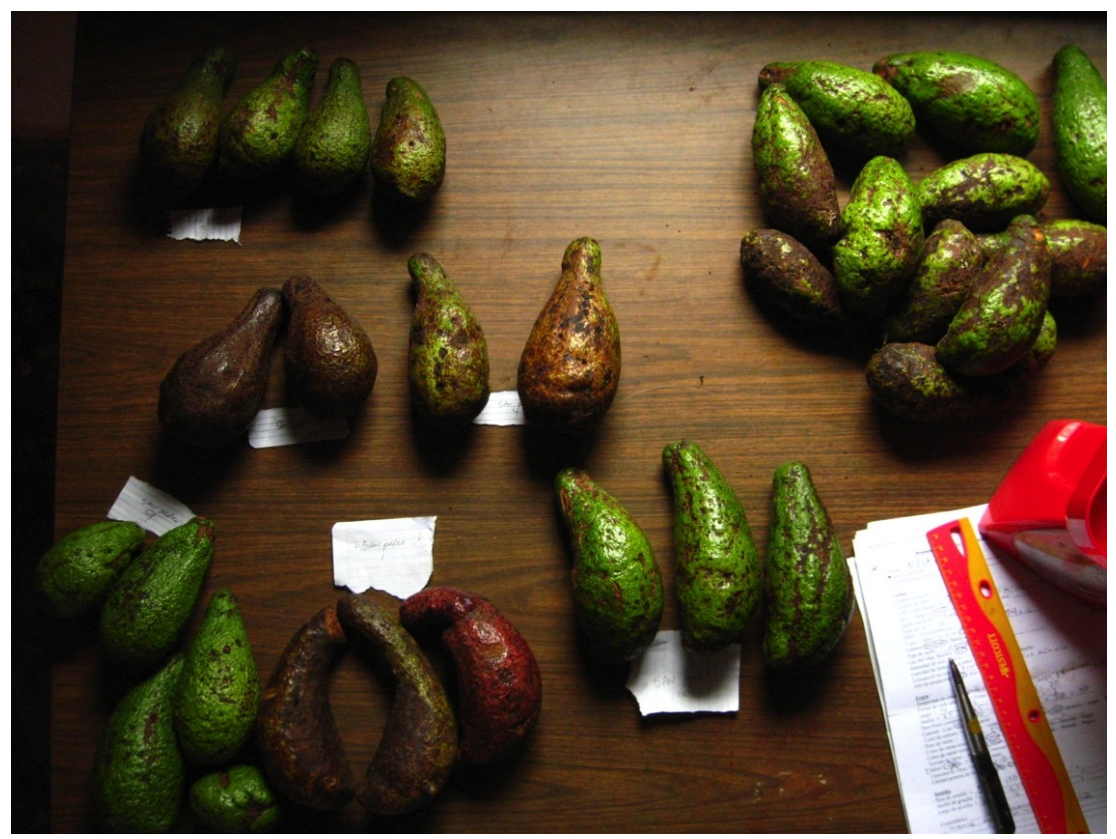

Most research to date on this species has focused on its potential use as a root stock for avocado owing to some evidence that it has tolerance to Phytophthora root rot (Phytophthora cinnamomi), the most significant avocado disease globally [25-29]. However, it is increasingly being recognized that Persea schiedeana has a value as an edible fruit in its own right, with opportunities for increased production to stimulate local economies through sale of fresh fruit locally and regionally and/or for its use in cooking oil production, for both local use and to market [24,30,31]. Avocado is itself experiencing a rapid growth for this use [32,33]. Persea schiedeana also has the potential to contribute to food security and local agricultural economies throughout the tropics via the introduction of superior selections.

Field research was carried out in 2008 in the Chinantla area of Oaxaca, Mexico, in the territory of six indigenous villages organized as CORENCHI (Comité de Recursos Naturales de la Chinantla Alta) $[34,35]$. These village territories are in highly biodiverse, mountainous areas unsuited for intensive annual agriculture. Historically, the area supports subsistence milpa agriculture and market-oriented, shade coffee production. Owing to the fluctuating coffee prices in the late 1990s and first decade of the 21st century, known as the Coffee Crisis [36], farmers in the area were seeking additional income sources, as well as increasingly out-migrating. This research was a collaborative project with local villages to (1) provide basic data on the agroecology and ethnoecology of Persea schiedeana; (2) document the morphological diversity of the Persea schiedeana fruits in the area; and (3) identify superior phenotypes to be "captured" through grafting and planted more widely in the villages as part of a "Participatory Domestication Project" [16,18]. The basic fruit morphology data is meant to complement the data collected on Persea schiedeana in neighboring states or Veracruz and Tabasco [21,24,31,37]. The agroecology and ethnoecological data is meant to fill the gap in the literature on these subjects and provide relevant information for those wishing to introduce the species into new areas. 


\section{Experimental}

Between February and July 2008, both management data and morphological data were collected on Persea schiedeana in the Chinantla area, specifically in the village of San Mateo Yetla and the six villages compromising CORENCHI (Santa Cruz Tepetotutla, San Antonio de El Barrio, Santiago Tlatepusco, San Pedro Tlatepusco, San Antonio Analco, and Nopalera del Rosario), using interviews and data collection on trees and their fruits.

\subsection{Interviews}

To obtain information on the ethnoecology and management of Persea schiedeana, an interview was elaborated and administered to a total of 34 people, of varying ages, both male and female, from all seven villages. The interview was partly inspired by similar work on another Mesoamerican species that blurs the line between cultivated and wild Sideroxylon palmeri [38]. The purpose of the interview was to elicit information about how the diversity of Persea schiedeana is perceived and managed, as well as local knowledge of its ecology and ecological interactions. In a participatory domestication program, the local knowledge of the species in question is regarded as one of the most important fonts of information in regards to local diversity, ecological preferences, superior individuals, and usage [16]. The answers to many of the questions were subsequently coded numerically and percentages of each answer calculated. Other answers were used as free list data to analyze in the program ANTHROPAC [39].

\subsection{Fruit Morphology and Diversity}

In each of the villages of CORENCHI, data was collected on trees and fruits during late May and June 2008, the early and middle part of harvest season of Persea schiedeana in the Chinantla area. Local research assistants were trained in each village prior to data collection to aid in the collection of data and to help in interaction with the communities. The training of research assistants and their paid assistance was a stipulation by the communities to research in their villages and territory, so that resources, both intellectual and monetary, are accrued by the communities.

An attempt was made to locate all trees in each village's territory. Information on each tree and its location was collected in the field, including GPS coordinates, relative estimated levels of sunlight reaching canopy, relative soil humidity of growing sites, estimated yield in number of fruits, type of agroecosystem, whether the tree was planted or arose spontaneously, and the soil type, according to local classification. Fruits were either collected from the ground (if present) or retrieved from the tree by various means, such as climbing, rock and stick throwing, branch shaking, or sling shot, all typical ways that the fruit is harvested locally. An attempt to collect five fruits from each tree was made although it was not always proven possible.

Upon return to the village, data was recorded on the fruit exterior, i.e., color, skin texture, shape, weight, dimensions, etc. If the fruit was ripe, the fruit was cut open and data was recorded on the interior of the fruit. More typically, however, the fruit was not ripe and two to three days later, data was recorded on the interior part of the fruit. As part of this process of data collection on the interior of the fruit or immediately afterwards, "Chinene Fairs" were held in each of the villages, during which the fruits were publicly displayed and villagers were encouraged to examine and taste the fruits and 
voice their opinions concerning which were superior (Figure 3). The success of these fairs was mixed, in some villages serving quite well, in others only moderately well. In the best cases, participants collectively decided upon the best fruits of the village. In other cases, the researcher, along with research assistants, made the subjective determination as to the best fruits.

Figure 3. "Chinene Fair" in San Antonio Analco, during which the community participated in the selection of superior types for vegetative propagation.

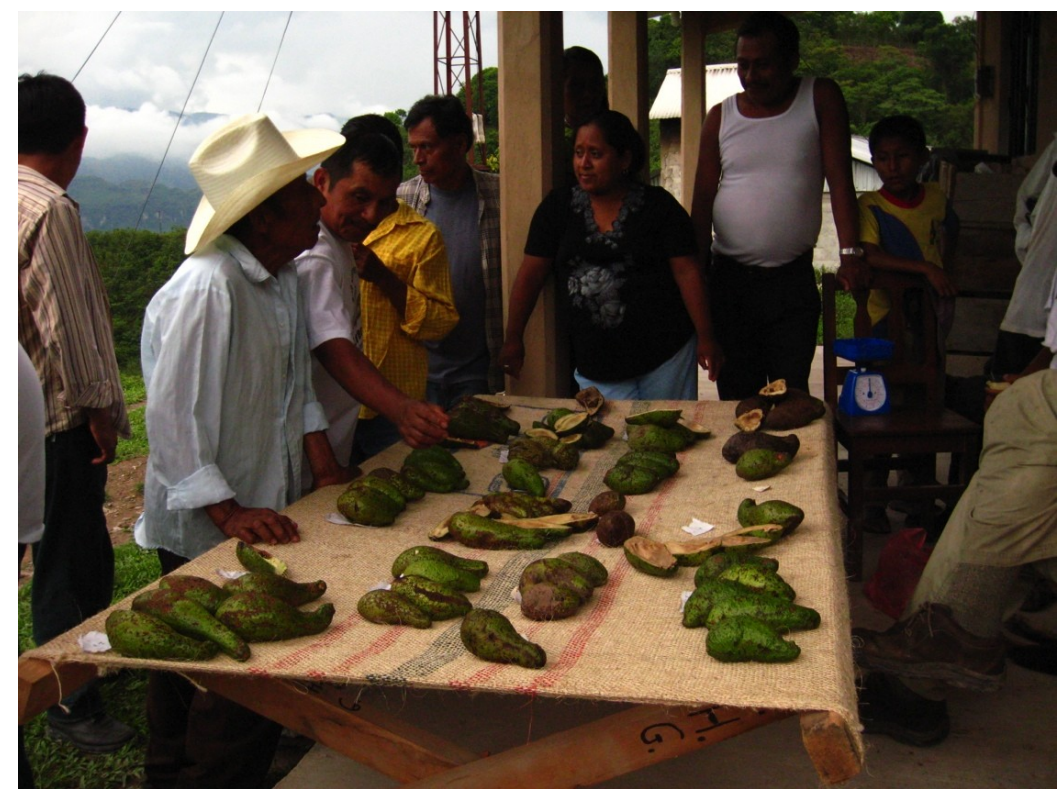

\section{Results and Discussion}

\subsection{Tree/Fruit Data}

During research 124 trees were encountered in the territories of the five villages under study, which are thought to represent the majority of the trees in villages composing CORENCHI's territory. During nearly two years of research on Persea schiedeana (including the period of this research and previously exploratory trips to the area), the following general phenological cycle was observed as shown in Table 1 (with the dates varying considerably depending upon altitude; trees in lower/hotter climates reach each phase earlier). Data was collected on each of the 124 individual trees and the sites in which they were encountered during research in the six villages, and is summarized in Tables 2 and 3.

Table 1. Phenological stages of Persea schiedeana in the villages composing CORECNHI, Chinantla, Oaxaca, Mexico. Observed 2007-2008.

\begin{tabular}{cl}
\hline Month & Phenological Stage \\
\hline January-March: & Terminal bud-break and flowering, followed by flush of new foliage. \\
February-March: & Dropping of old leaves, maturation of new leaves. \\
May-August: & Fruiting \\
& Second flush of foliage and sporadic re-flowering \\
August-December: & (reports of rare fruiting in February from this flowering) \\
& Best time for grafting \\
December-January: & Rootstock can be generated from seed in June-July to grafting size in January. \\
Note: &
\end{tabular}


Table 2. Pooled data on trees of Persea schiedeana in the villages composing CORENCHI, Chinantla area, Oaxaca, Mexico 2008. Estimated age of tree, altitude above sea level at which tree encountered, diameter at breast height (DBH), and estimated height of trees.

\begin{tabular}{ccccc}
\hline & Age $(\boldsymbol{n}=\mathbf{1 1 7})$ & Altitude $(\boldsymbol{n}=\mathbf{1 1 8})$ & DBH $(\boldsymbol{n}=\mathbf{1 2 4})$ & Height $(\boldsymbol{n}=\mathbf{3 4})$ \\
\hline Overall Mean & $32.5 \pm 22$ & $733 \mathrm{~m} \pm 235$ & $50 \mathrm{~cm} \pm 27$ & $21 \mathrm{~m} \pm 9$ \\
Maximum & 100 years & $1193 \mathrm{~m}$ & $153 \mathrm{~cm}$ & $45 \mathrm{~m}$ \\
Minimum & 8 years & $255 \mathrm{~m}$ & $15 \mathrm{~cm}$ & $5 \mathrm{~m}$ \\
\hline
\end{tabular}

Table 3. Estimated ecological characteristics (utilizing local classifications) of sites where Persea schiedeana trees found in the village composing CORENCHI, Chinantla, Oaxaca, Mexico 2008.

\begin{tabular}{|c|c|c|c|c|c|c|}
\hline \multicolumn{7}{|c|}{ Characteristic } \\
\hline $\begin{array}{l}\text { Soil type } \\
(n=120)\end{array}$ & $\begin{array}{c}\text { Abonoso/ } \\
\text { Organic: } 29 \%\end{array}$ & $\begin{array}{c}\text { Negra/ } \\
\text { Black: } 53 \%\end{array}$ & $\begin{array}{c}\text { Media/ } \\
\text { Medium: } 1 \%\end{array}$ & $\begin{array}{c}\text { Amarilla/ } \\
\text { Yellow: } 6 \%\end{array}$ & $\begin{array}{c}\text { Arenosa/ } \\
\text { Sandy: } 7 \%\end{array}$ & $\begin{array}{c}\text { Segunda/ } \\
\text { Second: } 5 \%\end{array}$ \\
\hline $\begin{array}{l}\text { Humidity } \\
\text { of site } \\
(n=123)\end{array}$ & Driest: $0 \%$ & Dry: $7 \%$ & Medium: 39\% & Humid: 47\% & $\begin{array}{c}\text { Hyper-humid: } \\
7 \%\end{array}$ & \\
\hline $\begin{array}{l}\text { Light level } \\
\text { of site } \\
(n=116)\end{array}$ & Shade: $21 \%$ & Sun: $79 \%$ & & & & \\
\hline
\end{tabular}

As expected from interviews, Persea schiedeana was not found evenly distributed throughout the territory of the villages, but was rather concentrated in coffee growing areas where it is used as a shade tree (Figure 4). The other six of the seven ecosystems recognized within the villages had low to moderate presence of $P$. schiedeana, with the forest fragments having $20 \%$.

Figure 4. Agroecosytems in which Persea schiedeana trees were encountered in villages composing CORENCHI, Chinantla, Oaxaca, Mexico 2008.

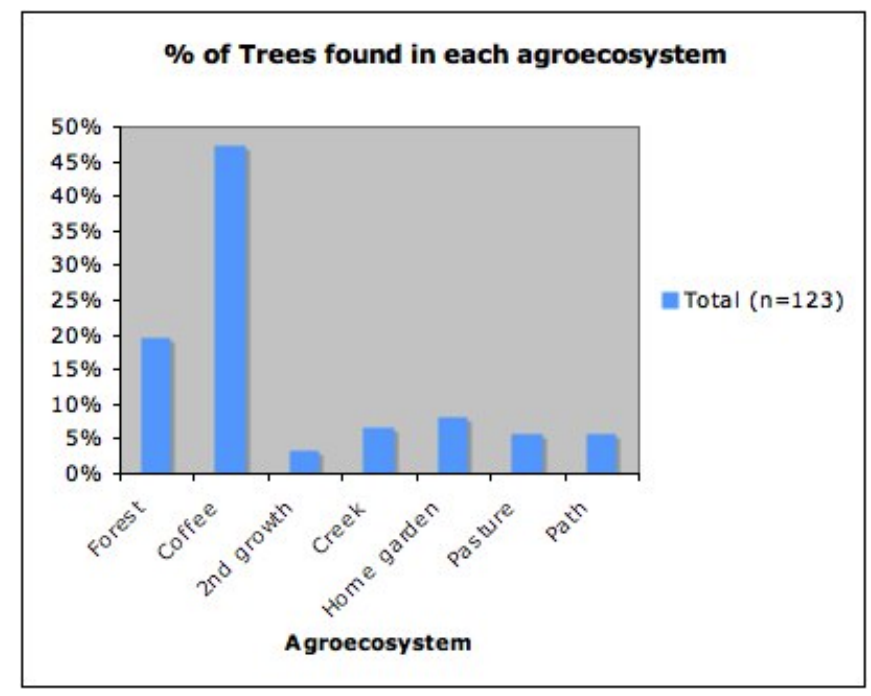

The overall phenotypic data collected on Persea schiedeana fruits in the six villages is summarized in Table 4, while a quantitative comparison of "planted" versus "self-sown" populations of trees is presented in Table 5. 
Table 4. Summary of quantitative and qualitative fruit characters of Persea schiedeana (chinene) measured in 2008 in the villages composing CORENCHI, Chinantla, Oaxaca, Mexico.

\begin{tabular}{|c|c|c|c|c|c|c|}
\hline \multicolumn{7}{|l|}{ Fruit Character: } \\
\hline & \multicolumn{2}{|c|}{ Number of fruits } & \multicolumn{2}{|c|}{ Average (Standard Deviation) } & \multicolumn{2}{|c|}{ Min/Max } \\
\hline Fruit Length (cm) & & 487 & \multicolumn{2}{|c|}{$14 \pm 3.6$} & \multicolumn{2}{|c|}{$8-28$} \\
\hline Fruit Width (cm) & & 485 & \multicolumn{2}{|c|}{$6 \pm-1$} & \multicolumn{2}{|c|}{$3-10$} \\
\hline Fruit Weight (g) & & 484 & \multicolumn{2}{|c|}{$297 \pm 112$} & \multicolumn{2}{|c|}{$90-1000$} \\
\hline Pulp + Skin Weight (g) & & 195 & \multicolumn{2}{|c|}{$211 \pm 75$} & \multicolumn{2}{|c|}{$80-440$} \\
\hline Seed Length (cm) & & 194 & \multicolumn{2}{|c|}{$9 \pm 2$} & \multicolumn{2}{|c|}{$3-17$} \\
\hline Seed Width (cm) & & 197 & \multicolumn{2}{|c|}{$4 \pm 1.3$} & \multicolumn{2}{|c|}{$2-13$} \\
\hline Seed Weight (g) & & 209 & \multicolumn{2}{|c|}{$91 \pm 43$} & \multicolumn{2}{|c|}{$30-240$} \\
\hline Pulp + Skin: Seed Ratio & & 192 & \multicolumn{2}{|c|}{$2.6 \pm 1.4$} & \multicolumn{2}{|c|}{$0.6-10$} \\
\hline \multicolumn{7}{|c|}{ Qualitative fruit characters } \\
\hline Fruit Form & 90 & Long neck: $20 \%$ & Pyriform: $45 \%$ & Ball: $12 \%$ & $\begin{array}{l}\text { Pyriform } \\
\text { w/neck: } 21 \%\end{array}$ & $\begin{array}{l}\text { Cucumber: } \\
2 \%\end{array}$ \\
\hline Fruit Pulp Texture & 83 & Watery: $21 \%$ & Creamy: $77 \%$ & Floury: $2 \%$ & & \\
\hline Flavor & 83 & Best: $45 \%$ & Good: $24 \%$ & OK: $19 \%$ & Poor: $12 \%$ & Bad: $0 \%$ \\
\hline Fiber Content & 86 & None: $15 \%$ & Low: $51 \%$ & Medium: $21 \%$ & High: $12 \%$ & Extreme: $1 \%$ \\
\hline Subjective Quality & 83 & Best: $36 \%$ & Good: $36 \%$ & Average: $18 \%$ & Poor: $9 \%$ & Bad: $1 \%$ \\
\hline
\end{tabular}

Table 5. Comparison of planted and self-sown fruits.

\begin{tabular}{|c|c|c|c|}
\hline Planted vs. Self Sown & Planted & Self-Sown & Significance \\
\hline Skin Color $(n=44,44)$ & $\begin{array}{l}\text { LG:61.4\%, DG:25.0\%,P:11.4\%, } \\
\text { R:2.3\% }\end{array}$ & $\begin{array}{l}\text { LG: } 84.1 \%, \text { DG: } 15.9 \%, \\
\text { P:0.0\%, R:0.0\% }\end{array}$ & No data \\
\hline Pulp Texture $(n=37,40)$ & $\mathrm{W}: 20.5 \%, \mathrm{Cr}: 77.1 \%, \mathrm{Fl}: 2.4 \%$ & $\mathrm{~W}: 24.3 \%, \mathrm{Cr}: 73.0 \%, \mathrm{Fl}: 2.7 \%$ & No data \\
\hline Flavor $(n=36,41)$ & $1.56 \pm 0.135$ & $2.44 \pm 0.175$ & 0 \\
\hline Fiber $(n=38,42)$ & $2.61 \pm 0.139$ & $2.07 \pm 0.138$ & 0.008 \\
\hline Quality $(n=37,41)$ & $1.68 \pm 0.140$ & $2.39 \pm 0.160$ & 0.001 \\
\hline Fruit Form $(n=58,24)$ & $\begin{array}{l}1: 20.7 \%, 2: 43.1 \%, 3: 12.1 \% \\
4: 22.4 \%, 5: 1.7 \%\end{array}$ & $\begin{array}{l}\text { 1: } 20.8 \%, 2: 50.0 \%, 3: 16.7 \% \\
4: 12.5 \%, 5: 0.0 \%\end{array}$ & No data \\
\hline Fruit Length $(n=225,224)$ & $14.4 \mathrm{~cm} \pm 0.2$ & $13.7 \mathrm{~cm} \pm 0.2$ & 0.022 \\
\hline Fruit Width $(n=224,223)$ & $6.4 \mathrm{~cm} \pm 0.07$ & $6.1 \mathrm{~cm} \pm 0.07$ & 0.028 \\
\hline Fruit Weight $(n=226,220)$ & $313 \mathrm{~g} \pm 8$ & $280 \mathrm{~g} \pm 7$ & 0.002 \\
\hline Pulp/Skin Weight $(n=123,54)$ & $223 \mathrm{~g} \pm 7$ & $187 \mathrm{~g} \pm 9$ & 0.003 \\
\hline Seed Weight $(n=123,62)$ & $101 \mathrm{~g} \pm 4$ & $79 \mathrm{~g} \pm 4$ & 0.001 \\
\hline Pulp: Seed Ratio $(n=121,53)$ & $2.62 \mathrm{~g} \pm 0.13$ & $2.61 \mathrm{~g} \pm 0.2$ & 0.969 \\
\hline Best vs.Rest & Best: $15.6 \%$, Rest: $84.4 \%$ & Best: $8.0 \%$, Rest: $92.6 \%$ & No data \\
\hline
\end{tabular}

Skin Color: $\mathrm{LG}=$ light green, $\mathrm{DG}=$ dark green, $\mathrm{P}=$ purple/black, $\mathrm{R}=$ red; Pulp Texture: $\mathrm{W}=$ watery, $\mathrm{Cr}=\mathrm{creamy}$, $\mathrm{Fl}=$ Flour; Fruit Form: 1 = Long neck, 2 = Pyriform, 3 = Ball, 4 = Medium neck, 5 = Cucumber.

Figure 5 compares the fruits of planted trees with the non-planted trees, also including the overall averages, the "ideotype" according to traits elicited in interviews and the "best" fruit producing trees. Villagers chose the "best" during "Chinene Fairs" where fruits from all the trees in the village were displayed and sampled and consensus was reached on the "best". The planted trees were statistically superior for all quantitative traits, except seed to pulp ratio, in which it was equal to self-sown fruits. 
Figure 5. Graphical comparison of the "ideotype" or ideal chinene, as elicited from interviews with the "average", that is average of all P. schiedeana fruits in the study, the "planted" and "self-sown" sub-divisions of the total, and the "best" as selected during "Chinene Fairs".

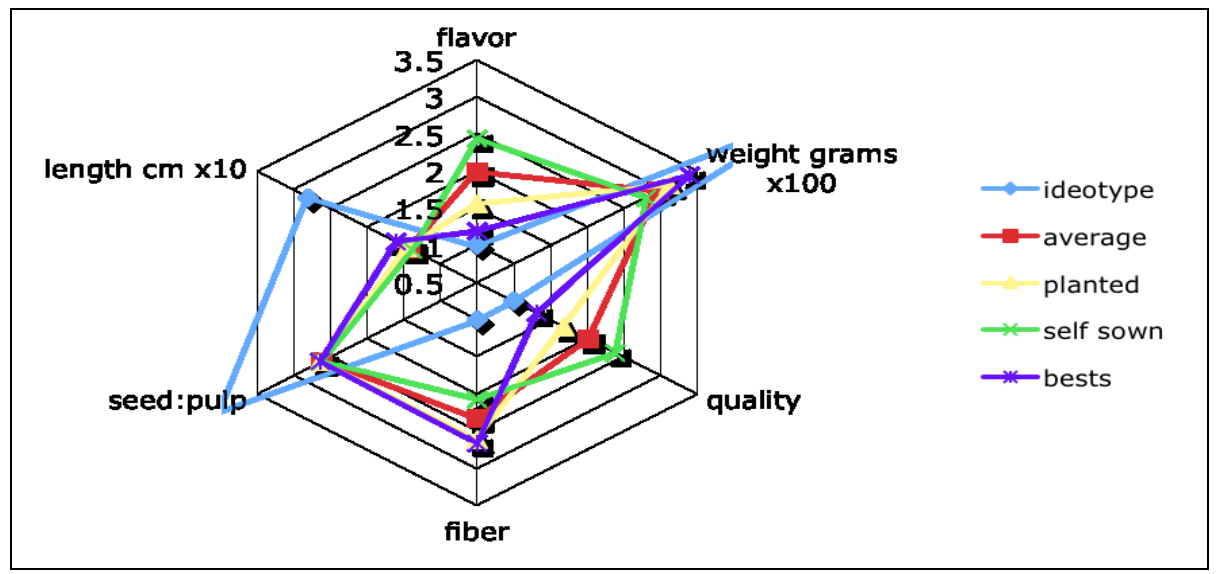

\subsection{Ethnoecology and Management}

A total of 34 interviews were carried out among the five villages composing CORENCHI. The interviews revealed considerable traditional ecological knowledge (TEK) about Persea schiedeana, and also provided information concerning traditional management techniques and selective criteria that are applied to the species.

Seventy-nine percent of respondents reported that they harvest the fruits of P. schiedeana. Of these, $32 \%$ report that they harvest the fruit by climbing the trees and cutting the fruit, while $29 \%$ report more casually looking for the fallen fruits under the trees, and 39\% report utilizing both of the strategies to obtain the fruits. During the harvest period (late May to early August), informants reported eating on average three fruits per day. Use of the tree for timber or firewood is not high, and no medicinal uses were reported nor use of the tree as fodder. Only $32 \%$ of respondents reported selling chinene, with the majority of those selling it within the village, at the average price of 3 pesos $(\$ 0.30)$ per fruit.

In regards to whether chinene is cultivated or only wild harvested, the interviews revealed that $85 \%$ of respondents reported having planted it from seed, $66 \%$ of these typically plant it directly as seed in the place where they desired to have the plant, while $15 \%$ reported starting the tree first in a home/nursery. Ninety-one percent of those who had planted chinene asserted that selection is made as to seed material based on the criteria in Table 6.

One hundred percent of informants reported that chinene also frequently comes up on its own without being planted. While such trees are sometimes near the mother tree, the fruits and seeds are regarded to frequently be distributed by a number of animals, with Tepezcuintle (Cuniculus paca), Tejon/Coati (Nasua narica) and Serete/Agouti (Dasyprocta sp.) mentioned most frequently as dispersers. These results show that two subpopulations exist within the territories of CORENCHI, purposely sown and incidentally/wild generated trees. 
Table 6. Selection criteria elicited from interviews.

\begin{tabular}{ccc}
\hline Selective Criteria $(\boldsymbol{n}=\mathbf{3 1})$ & \# of Times Listed & Percent of Informants to List \\
\hline "Best"/"Mejor" (overall) & 18 & 58 \\
Good flavor & 7 & 23 \\
High pulp content & 6 & 19 \\
Large fruit & 4 & 13 \\
\hline
\end{tabular}

The most important and widely executed management technique is "protecting" trees sensu Casas et al. [40] both young and old, from competition for light from other trees and, in the case of older trees, lianas. Ninety-four percent of respondents reported this as a management practice employed with chinene, whereas $22 \%$ reported pruning or rather tipping of saplings being a management technique employed to try to promote branching and dwarfed stature, and only $18 \%$ reported any irrigation of young trees to aid in establishment.

\subsection{Traditional Knowledge of Phenology and Ecology}

In terms of knowledge of phenology and ecology of $P$. schiedeana from interviews, the average juvenility period reported was nine years $( \pm 4)$. Seventy-four percent reported that flowering and fruiting occurs at the same time of the year for all trees in the area, while the remainder indicated that some minor variation was to be found, principally owing to the conditions of the site. Likewise, 54\% reported that the quantity of fruits that trees produce varies and $65 \%$ that the juvenility period can vary, both according to environmental conditions. It was frequently stated that the trees prefer moist sites with soils rich in organic matter. Ninety-seven percent of respondents reported that chinene is strongly biennial in its cropping pattern, though there were a few anecdotal reports of trees (especially in home gardens) that yield equally each year. Ninety-seven percent responded negatively to the question as to whether they felt that avocado (Persea americana) and chinene can cross and/or they have observed any trees with intergrading characteristics.

\section{Conclusions}

The information reported here expands the specific information available in the literature on Persea schiedeana, its morphology, agroecology, and ethnoecology and management. The interviews revealed Persea schiedeana is important in the agricultural systems and diets in the villages composing CORENCHI. In terms of dietary role, those interviewed reported that they eat on average three fruits per day during the harvest season (late May to early August, depending on altitude), which significantly falls during the time that maize supplies are diminishing from the last harvest and just prior to the season of local avocado (Persea americana) varieties (July to September), which is in turn followed by Beilshmiedia anay (late October to December). The contribution to local food security from chinene in terms of calories and fatty acids is thus proposed to be substantial, though not quantified relative to total caloric intake in this study.

In terms of its agroecological role, this research shows that Persea schiedeana is found most abundantly in coffee groves, where it is a multipurpose species, providing both food and shade for coffee plants. Its utility as a multipurpose tree in other tropical areas of the world is worthy of being promoted. 
As with many indigenous fruit tree species managed as part of traditional agroforestry systems, a considerable amount of morphological diversity in the fruit exists, partly a result of human selection. This research shows that Persea schiedeana is purposely cultivated. It further suggests that it is incipiently domesticated sensu Clement [41] and demonstrates that a number of management techniques typical of early stages of domestication are applied to the trees [40]. It shows that conscious selection is taking place when seeds are sown and suggests that such past selection has had a minor phenotypic effect on the fruits, seen as statistically significant differences between the planted and self-sown fruits for all quantitative characters other than seed to pulp ratio.

The superior types, while traditionally seed propagated, could be more reliably and quickly reproduced via grafting in a participatory domestication project similar to those carried out in West Africa and the Amazon with native fruit species from these areas [18,42]. It is recommended that areas importing Persea schiedeana as a novel crop seek scion of superior trees to graft onto either Persea schiedeana root stock or Persea americana rootstock with which it is compatible (Cruz-Castillo 2012 per. com.)

Future research needs are to add to the small but growing dataset on Persea schiedeana represented by this work and previous published studies from Tabasco and Veracruz, Mexico [21,24] through similar research in southern Mexico, Central America, and Colombia. Research on the genetic diversity of Persea schiedeana and its relations with other Persea species will help to better understand the species, its past and direct improvement programs. Research on grafting and rootstock/scion interactions is nearly non-existent and will be needed for this crop to move into wider cultivation. Lastly, further development of oil extracting equipment as it is being applied to Persea americana will be relevant to Persea schiedeana if it is to be utilized as an oil crop [33,43].

\section{Acknowledgments}

Many thanks to the collaborators in the villages of CORENCHI, David Bray (FIU) and Elvira Duran (CIIDIR Oaxaca), Carlos del Campo and Claudia Camacho of Global Diversity Foundation, and Hugh Popenoe, Nigel Smith, and Walter Judd of University of Florida. Thank to Charles Clement for comments on an early manuscript.

\section{Conflicts of Interest}

The author declares no conflict of interest.

\section{References}

1. Hammer, K.; Arrowsmith, N.; Gladis, T. Agrobiodiversity with emphasis on plant genetic resources. Naturwissenschaften 2003, 90, 241-250.

2. Burlingame, B.; Charrondiere, U.R.; Dernini, S.; Stadlmayr, B.; Mondovì, S. Food Biodiversity and Sustainable Diets: Implications of Applications for Food Production and Processing. In Green Technologies in Food Production and Processing; Boye, J.I., Arcand, Y., Eds.; Food Engineering Series, Springer: New York, NY, USA, 2012; pp. 643-657.

3. Heywood, V.H. Ethnopharmacology, food production, nutrition and biodiversity conservation: towards a sustainable future for indigenous peoples. J. Ethnopharmacol. 2011, 137, 1-15. 
4. Thrupp, L.A. Linking agricultural biodiversity and food security: The valuable role of agrobiodiversity for sustainable agriculture. Int. Aff. 2000, 76, 283-297.

5. Frison, E.A.; Cherfas, J.; Hodgkin, T. Agricultural Biodiversity is essential for a sustainable improvement in food and nutrition security. Sustainability 2011, 3, 238-253.

6. Hills, K.; Goldberger, J.; Jones, S. Commercial bakers and the relocalization of wheat in western Washington State. Agric. Hum. Values 2013, 30, 365-378.

7. Veteto, J. Seeds of Persistence. PH.D. Dissertation, University of Georgia: Athens, GA, USA, 2010.

8. Petrini, C. Slow Food Revolution: A New Culture for Eating and Living; Rizzoli: New York, NY, USA, 2006.

9. Nazarea, V.D. Cultural Memory and Biodiversity; University of Arizona Press: Tucson, AZ, USA, 2005.

10. Padulosi, S.; Hodgkin, T.; Williams, J.T.; Haq, N. Underutilized Crops: Trends, Challenges and Opportunities in the 21st Century. In Managing Plant Genetic Diversity; Engels, J., Rao, V., Brown, A., Jackson, M., Eds.; CAB International: Wallingford, UK, 2002.

11. Leakey, R.R.B.; Newton, A.C. Domestication of "Cinderella" Species as the Start of a Woody-Plant Revolution. In Tropical Trees: The Potential for Domestication and the Rebuilding of Forest Resources; Leakey, R.R.B., Newton, A.C., Eds.; HMSO: London, UK, 1993; pp. 3-7.

12. Prance, G.T. Amazonian Tree Diversity and the Potential for Supply of Non-Timber Forest Products. In Tropical Trees: Potential for Domestication and the Rebuilding of Forest Resources; Leakey, R.R.B., Newton, A.C., Eds.; HMSO: London, UK, 1994; Volume 29, p. 7.

13. Leakey, R.R.B.; Temu, A.B.; Melnyk, M.; Vantomme, P. Domestication and commercialization of non-timber forest products in agroforestry systems. Available online: http://www.fao.org/ docrep/w3735e/w3735e00.HTM (assessed on 18 December 2013).

14. Leakey, R.R.B.; Simons, A.J. The domestication and commercialization of indigenous trees in agroforestry for the alleviation of poverty. Agrofor. Syst. 1997, 38, 165-176.

15. Schreckenberg, K.; Awono, A.; Degrande, A.; Mbosso, C.; Ndoye, O.; Tchoundjeu, Z. Domesticating indigenous fruit trees as a contribution to poverty reduction. For. Trees Livel. 2006, 16, 35-51.

16. Leakey, R.R.B.; Akinnifesi, F.K. Towards a Domestication Strategy for Indigenous Fruit Trees in the Tropics. In Indigenous Fruit Trees in the Tropics: Domestication, Utilization and Commercialization; Akinnifesi, F.K., Leakey, R.R.B., Ajayi, O.C., Sileshi, G., Tchoundjeu, Z., Matakala, P., Kwesiga, F.R., Eds.; CAB International: Wallingford, UK, 2007; pp. 28-49.

17. Simons, A.J.; Leakey, R.R.B. Tree domestication in tropical agroforestry. Agrofor. Syst. 2004, 62, $167-181$.

18. Clement, C.R.; Cornelius, J.P.; Pinedo-Panduro, M.H.; Yuyama, K. Native Fruit Tree Improvement in Amazonia: An Overview. In Indigenous Fruit Trees in the Tropics: Domestication, Utilization and Commercialization; Akinnifesi, F.K., Leakey, R.R.B., Ajayi, O.C., Sileshi, G., Tchoundjeu, Z., Matakala, P., Kwesiga, F.R., Eds.; CAB International: Wallingford, UK, 2007; pp. 100-119.

19. Zizumbo-Villarreal, D.; Flores-Silva, A.; Marín, P.C.-G. The Archaic diet in mesoamerica: Incentive for milpa development and species domestication. Econ. Bot. 2012, 66, 328-343. 
20. Bost, J. Edible Plants of the Chinantla, Oaxaca, Mexico with an Emphasis on the Participatory Domestication Prospects of Persea Schiedeana. Master Thesis, University of Florida: Gainesville, FL, USA, 2009.

21. De la Medina, C.J.S.; Castillo, C.J.G.; Martínez, J.M.; del Coronel, Ó.Á. Distribución ecogeográfica y características del fruto de persea schiedeana nees. en los Tuxtlas, Veracruz, México. Rev. Fitotec. Mex. 2007, 30, 403-410, (in Spanish).

22. Smith, N.J.H.; Williams, J.T.; Plucknett, D.; Talbott, J. Tropical Forests and Their Crops; Comstock Pub. Associates: Ithaca, NY, USA, 1992.

23. Popenoe, W. Manual of Tropical and Subtropical Fruits Excluding the Banana, Coconut, Pineapple, Citrus Fruits, Olive, and Fig; Macmillan Co.: New York, NY, USA, 1924.

24. Castillo, C.J.G.; del Coronel, A.O.A.; de la Medina, C.J.; Martínez, J.M.C. Características morfológicas y bioquímicas de frutos de chinene (Persea schiedeana Nees.). Rev. Chapingo Ser. Hortic. 2007, 13, 141-147, (in Spanish).

25. Litz, R.E. Biotechnology of Fruit and Nut Crops; CABI: Cambridge, MA, USA, 2005.

26. Lahav, E.; Lavi, U. Genetics and Classical Breeding. In The Avocado: Botany, Production and Uses; Whiley, A., Schaffer, B., Wolstenholme, B., Eds.; CAB International: Wallingford, UK, 2002; pp. 39-69.

27. Coffey, M.D. Phytophthora root rot of avocado. Plant Dis. 1987, 71, 1046-1052.

28. Ellstrand, N.C.; Lee, J.M.; Bergh, B.O.; Coffey, M.D.; Zentmyer, G.A. Isozymes confirm hybrid parentage for 'G755' selections. Calif. Avocado Soc. Yearb. 1986, 70, 199-203.

29. Schroeder, C.A. Persea schiedeana, the coyo, a possible rootstock for avocado in South Africa. Calif. Avocado Soc. Yearb. 1974, 57, 18-23.

30. Angel-Coronel, O.A.D.; Cruz-Castillo, J.G.; Cruz-Medina, J.D.L.; Famiani, F. Ripening and physiological changes in the fruit of persea schiedeana nees during the postharvest period. HortScience 2010, 45, 172-175.

31. Castillo, C.J.G.; Gil, M.S.; de la Medina, C.J.S.; Castellanos, N.P.; Bracamontes, F.R.; Espinoza, J.P.; Martinez, L. El Chinene (Persea schiedeana Nees): buscando suvaloracion en Mexico contemporaneo. Aqui Centros Regionales 2004, 11, 1-7, (in Spanish).

32. Berasategi, I.; Barriuso, B.; Ansorena, D.; Astiasarán, I. Stability of avocado oil during heating: Comparative study to olive oil. Food Chem. 2012, 132, 439-446.

33. Wolfe, A.; Wong, M.; Eyres, L.; McGhie, T.; Lund, C.; Olsson, S.; Wang, Y.; Bulley, C.; Wang, W.; Friel, E.; et al. Avocado Oil. In Gourmet and Health Promoting Specialty Oils; Moreau, R., Kamal-Eldin, A., Eds.; AOCS Press: Urbana, IL, USA, 2009; pp. 73-126.

34. Bray, D.B.; Duran, E.; Anta, S.; Martin, G.; Mondragon, F. A new conservation and development frontier: community protected areas in Oaxaca, Mexico. Curr. Conserv. 2008, 2, 7-9.

35. Bray, D.; Duran, E.; Molina, O. Beyond harvests in the commons: multi-scale governance and turbulence in indigenous/community conserved areas in Oaxaca, Mexico. Int. J. Commons 2012, 6, 151-178.

36. Bacon, C.M. Confronting the Coffee Crisis: Fair Trade, Sustainable Livelihoods and Ecosystems in Mexico and Central America; MIT Press: Cambridge, MA, USA, 2008. 
37. Tenorio, M.; Flores, A.; Lopez de Jesus, P. Distribucion, Biologia Floral y Dicogamia (Persea Schiedeana Nees.) en la Region Centro del Estado de Veracruz. In Enfoques Tecnológicos en la Fruticultura, un Tributo a Raul Mosqueda (in Spanish); Cruz-Castillo, J.G., Torres Lima, P., Eds.; Universidad Autónoma de Chapingo: Chapingo, Mexico, 2008.

38. González-Soberanis, C.; Casas, A. Traditional management and domestication of tempesquistle, Sideroxylon palmeri (Sapotaceae) in the Tehuacán-Cuicatlán Valley, Central Mexico. J. Arid Environ. 2004, 59, 245-258.

39. Borgatti, S. Anthropac 4.0; Analytic Technologies: Natick, MA, USA, 1996.

40. Casas, A.; Otero-Arnaiz, A.; Perez-Negron, E.; Valiente-Banuet, A. In situ management and domestication of plants in mesoamerica. Ann. Bot. 2007, 100, 1101-1115.

41. Clement, C. 1492 and the loss of amazonian crop genetic resources. I. The relation between domestication and human population decline. Econ. Bot. 1999, 53, 188-202.

42. Akinnifesi, F.; Leakey, R.; Ajayi, O.; Sileshi, G.; Tchoundjeu, Z.; Matakala, P.; Kwesiga, F. Indigenous Fruit Trees in the Tropics: Domestication, Utilization and Commercialization; CAB International: Wallingford, UK, 2008.

43. Reddy, M.; Moodley, R.; Jonnalagadda, S.B. Fatty acid profile and elemental content of avocado (Persea americana Mill.) oil--effect of extraction methods. J. Environ. Sci. Health B 2012, 47, $529-537$.

(C) 2013 by the authors; licensee MDPI, Basel, Switzerland. This article is an open access article distributed under the terms and conditions of the Creative Commons Attribution license (http://creativecommons.org/licenses/by/3.0/). 